American Journal of Applied Sciences 7 (1): 89-94, 2010

ISSN 1546-9239

(C) 2010 Science Publications

\title{
Are There Smaller Leverage Effects in Less-Developed Markets? Evidence from an Oil Exporting Country
}

\author{
${ }^{1}$ Mosayeb Phalavani and ${ }^{2}$ Parinaz Ezzati \\ ${ }^{1}$ Department of Economics, University of Sistan and Baluchestan, Zahedan, Iran \\ ${ }^{2}$ Department of Economics, \\ School of Economics, University of Wollongong, NSW, 2522, Australia
}

\begin{abstract}
Problem statement: This study uses daily data from the Tehran Stock Market (TSM) to illustrate the nature of stock market volatility in an undeveloped and young stock market. Although most studies suggest that a negative shock to stock prices will generate more volatility than a positive shock of equal magnitude but there is no evidence of asymmetric effect in TSM. Determine the nature of stock market volatility in an oil exporting country. Approach: Trading in Tehran Stock Market (TSM) is based on orders sent by the brokers. The data consist of 2375 daily observations of the closing value of the Tehran stock market from 3/30/1998 to 5/04/2007. Our empirical finding shows that the unconditional variance is 0.18 but visual inspections of the time series suggests that volatility of the stock return rate displays the clustering phenomenon associated with GARCH processes. Results: The estimation and test results for all models suggest that the leverage effect term, $\gamma$, is not significant at 5\% level. Although, in Asym. CARCH model based on normal distribution for errors, the estimated coefficient on the asymmetry term is -0.066 with a z-statistics of -1.749 recognized as significant at $10 \%$ level, but it has the wrong sign. It seems that good news and bad news has the same effect on stock prices in TSM, a result that is contradictory to other studies for developed countries. Conclusion: The estimated models containing TARCH, EGARCH, asymmetric CARCH and PARCH with different assumptions on error distributions suggest no strong and significant asymmetric effect. There are some reasons for this finding: (1) In Iran with Islamic laws, debt contracts are illegal or at least not enforced and Iranian firms do not have any financial leverage. As a result, we would expect to find smaller leverage effects in volatility in Iran than in the United States, for example. In deed the institutional differences with western financial markets manifest themselves in different return characteristics. (2) Stock prices in the TSM by regulation and intervention cannot exceed from some range. The strong serial correlation in returns necessitating long lags in the mean equations is possibly due to such regulations. (3) The history of TSM is very short compared to other stock markets and the information flow in this market is very slow. The estimated coefficients on the expected risk (as a measure of the risk-return tradeoff) are not significant. These findings suggest that the TSM is not efficient.
\end{abstract}

Key words: Volatility, stock market, Iran stock market

\section{INTRODUCTION}

While most researchers agree that volatility is predictable in many asset markets (Bollerslev and Wooldridge, 1992; Bollerslev et al., 1992; Bollerslev et al., 1994); they differ on how this volatility predictability should be modeled. Over the past several decades the evidence for predictability has led to variety of approaches. The most interesting of these approaches are the "asymmetric" or "leverage" volatility models in which good news and bad news have different predictability for future volatility (Black,
1976; Campbell and Hentschel, 1992; Christle, 1982; Engle and Ng, 1993; Friedmann and Sanddorf-Köhle, 2002; Henry, 1998; Nelson, 1991; Pagan and Schwert, 1990). In most these studies researchers have documented strong evidence that volatility is asymmetric in equity markets: Negative returns are generally associated with upward revisions of the conditional volatility while positive returns are associated with smaller upward or even downward revisions of the conditional volatility (Cox and Ross, 1976; Dickey and Fuller, 1979; Engle and Ng, 1993; Kwiatkowski, 1992). Researchers (Black, 1976;

Corresponding Author: Mosayeb Phalavani, Department of Economics, University of Sistan and Baluchestan, Zahedan, Iran 
Am. J. Applied Sci., 7 (1): 89-94, 2010

Christle, 1982; Schwert, 1989) believe that the asymmetry could be due to changes in leverage in response to changes in the value of equity. Others have argued that the asymmetry could arise from the feedback from volatility to stock price when changes in volatility induce changes in risk premiums (Campbell and Hentschel, 1992; French et al., 1987; Pindyck, 1984; $\mathrm{Wu}, 2002)$ the presence of asymmetric volatility is most apparent during a market crisis when large declines in stock prices are associated with a significant increase in market volatility. Asymmetric volatility can potentially explain the negative skewness in stock return data, as discussed in (Harvey and Siddique, 1999)

In this study we compare the performance of Threshold ARCH (TARCH), Exponential GARCH (EGARCH), asymmetric Component ARCH (CARCH) and Power ARCH (PARCH) fitted to daily Tehran Stock Market (TSM) returns and test whether asymmetry is present. There are not any studies which focus explicitly on modeling the volatility in the TSM.

Modeling volatility: Let $R_{t}$ be the rate of return of a stock, or a portfolio of stocks from time t- 1 to $t$ and $\Omega_{\mathrm{t}-1}$ be the past Information set containing the Realized value of all relevant variables up to time $\mathrm{t}-1$. So the conditional mean and variance are $\mathrm{y}_{\mathrm{t}}=\mathrm{E}\left(\mathrm{R}_{\mathrm{t}} \mid \Omega_{\mathrm{t}}\right), \mathrm{h}_{\mathrm{t}}=\operatorname{var}\left(\mathrm{R}_{\mathrm{t}} \mid \Omega_{\mathrm{t}}\right) \quad$ respectively. Given this definition, the unexpected return at time $t$ is $\varepsilon_{t}=R_{t}-y_{t}$. In order to model the effect of $\varepsilon_{t}$ on returns we use ARCH models as summarized in Table 1 (Bollerslev et al., 1994). $\gamma>0$ indicates the presence of leverage effects in the conditional variance.

GARCH: The GARCH $(1,1)$ model; An unexpected decrease or increase in returns at time $t$ will generate an increase in the expected variability in the next period. The basic GARCH $(1,1)$ model is based on the assumption that forecasts of time varying variance depend on the lagged variance of the asset (Bollerslev, 1986):

$\sigma_{t}^{2}=\omega+\alpha \varepsilon_{t-1}^{2}+\beta \sigma_{t-1}^{2}$

where, $\omega \geq 0, \alpha \geq 0, \beta \geq 0$. The GARCH $(1,1)$ is weakly stationary if $\alpha+\beta<1$, $\varpi$ is the mean, $\varepsilon_{t-1}^{2}$ is the news about volatility from the previous period (The ARCH term) and $\sigma_{t-1}^{2}$ the conditional variance is the last period forecast variance (the GARCH term) that it must be nonnegative. The basic GARCH is symmetric and does not capture the asymmetry effect that is inherent in most stock markets return data also known as the "leverage effect". In the context of financial time series analysis the asymmetry effect refers to the characteristic of times series on asset prices that 'bad news' tends to increase volatility more than 'good news' (Nelson, 1991; Panagiotidis, 2002).

EGARCH: the natural logarithm of the conditional variance in the Exponential GARCH model is allowed to vary over time as a function of the lagged error terms and specifically it is designed to capture the asymmetry shock to the conditional variance.

The EGARCH (1, 1) model: (Henry, 1998; French et al., 1987):

$\log \left(\sigma_{t}^{2}\right)=\omega+\beta \log \left(\sigma_{t-1}^{2}\right)+\gamma \frac{\varepsilon_{t-1}}{\sigma_{t-1}}+\alpha\left[\frac{\left|\varepsilon_{t-1}\right|}{\sigma_{t-1}}-\sqrt{\frac{2}{\pi}}\right]$

The exponential nature of the EGARCH ensures that the conditional variance is always positive even if the parameter values are negative, thus there is no need for parameter restrictions to impose nonnegativity. $\gamma$ captures the asymmetric effect.

Table 1: ARCH models

\begin{tabular}{ll}
\hline Model & Specification \\
\hline Exponential GARCH (EGARCH) & $\log \left(\sigma_{\mathrm{t}}^{2}\right)=\omega+\beta \log \left(\sigma_{\mathrm{t}-1}^{2}\right)+\gamma \frac{\varepsilon_{\mathrm{t}-1}}{\sigma_{\mathrm{t}-1}}+\alpha\left[\frac{\varepsilon_{\mathrm{t}-1} \mid}{\sigma_{\mathrm{t}-1}}-\sqrt{\frac{2}{\pi}}\right]$ \\
Threshold GARCH (TGARCH) & $\sigma_{\mathrm{t}}^{2}=\omega+\beta \sigma_{\mathrm{t}-1}^{2}+\alpha \varepsilon_{\mathrm{t}-1}^{2}+\gamma \mathrm{S}_{\mathrm{t}-1} \varepsilon_{\mathrm{t}-1}^{2}$ \\
& $\mathrm{~S}_{\mathrm{t}}=1$ if $\varepsilon_{\mathrm{t}}<0, \mathrm{~S}_{\mathrm{t}}=0$ otherwise \\
Component GARCH (CGARCH) & $\left\{\begin{array}{c}\sigma_{\mathrm{t}}^{2}-\mathrm{q}_{\mathrm{t}-1}=\alpha\left(\varepsilon_{\mathrm{t}-1}^{2}-\mathrm{q}_{\mathrm{t}-1}\right)+\beta\left(\sigma_{\mathrm{t}-1}^{2}-\mathrm{q}_{\mathrm{t}-1}\right) \\
\mathrm{q}_{\mathrm{t}}=\omega+\rho\left(\mathrm{q}_{\mathrm{t}-1}-\omega\right)+\phi\left(\varepsilon_{\mathrm{t}-1}^{2}-\sigma_{\mathrm{t}-1}^{2}\right)\end{array}\right.$ \\
Asymmetric CGARCH (ACGARCH) & $\mathrm{q}_{\mathrm{t}}=\omega+\rho\left(\mathrm{q}_{\mathrm{t}-1}-\omega\right)+\phi\left(\varepsilon_{\mathrm{t}-1}^{2}-\sigma_{\mathrm{t}-1}^{2}\right)+\theta_{1} \mathrm{z}_{1 \mathrm{t}}$ \\
& $\sigma_{\mathrm{t}}^{2}-\mathrm{q}_{\mathrm{t}-1}=\alpha\left(\varepsilon_{\mathrm{t}-1}^{2}-\mathrm{q}_{\mathrm{t}-1}\right)+\gamma\left(\varepsilon_{\mathrm{t}-1}^{2}-\mathrm{q}_{\mathrm{t}-1}\right) \mathrm{d}_{\mathrm{t}-1}+\beta\left(\sigma_{\mathrm{t}-1}^{2}-\mathrm{q}_{\mathrm{t}-1}\right)+\theta_{2} \mathrm{z}_{2 \mathrm{t}}$ \\
& $\sigma_{\mathrm{t}}^{\rho}=\omega+\beta \sigma_{\mathrm{t}-1}^{\rho}+\alpha\left(\left|\varepsilon_{\mathrm{t}-1}\right|-\gamma \varepsilon_{\mathrm{t}-1}\right)^{\rho}$
\end{tabular}


TGARCH: The Threshold GARCH model is based on the assumption that unexpected changes in the market returns have different effects on the conditional variance of the returns and as EGARCH model, specifically it is designed to capture the asymmetry shock to the conditional variance. Good news goes with an unforeseen increase and hence will contribute to the variance through the coefficient $\beta$ instead of an unexpected decrease which is presented as a bad news and contributes to the variance with the coefficient $\alpha+\gamma$. If $\gamma>0$ the leverage effect exists and news impact is asymmetric if $\gamma \neq 0$. The TGARCH modifies the original GARCH specification using a dummy variable (Nelson, 1991; Glosten et al., 1993):

$$
\begin{gathered}
\sigma_{\mathrm{t}}^{2}=\omega+\beta \sigma_{\mathrm{t}-1}^{2}+\alpha \varepsilon_{\mathrm{t}-1}^{2}+\gamma \mathrm{S}_{\mathrm{t}-1} \varepsilon_{\mathrm{t}-1}^{2} \\
\mathrm{~S}_{\mathrm{t}-1}=1 \quad \text { if } \varepsilon_{\mathrm{t}}<0 \\
\mathrm{~S}_{\mathrm{t}-1}=0 \quad \text { otherwise }
\end{gathered}
$$

CGARCH: Component GARCH; In order to allow for time varying persistence in the volatility dynamics, it is suggested to use a modification of the component GARCH model proposed by (Ding and Granger, 1996) in which the weights associated to the model components are time varying and depend on adequately chosen state variables such as lagged values of the conditional standard deviation:

$$
\begin{aligned}
& \sigma_{\mathrm{t}}^{2}=\mathrm{q}_{\mathrm{t}-1}=\alpha\left(\varepsilon_{\mathrm{t}-1}^{2}-\mathrm{q}_{\mathrm{t}-1}\right)+\beta\left(\sigma_{\mathrm{t}-1}^{2}-\mathrm{q}_{\mathrm{t}-1}\right) \\
& \mathrm{q}_{\mathrm{t}}=\omega+\mathrm{P}\left(\mathrm{q}_{\mathrm{t}-1}-\omega\right)+\varnothing\left(\varepsilon_{\mathrm{t}-1}^{2}-\sigma_{\mathrm{t}-1}^{2}\right)
\end{aligned}
$$

ACGARCH: Asymmetric CGARCH; asymmetric GARCH models due to the leverage effect with asset prices, where a positive shock has less effect on the conditional variance compared to a negative shock. This can be incorporated into the GARCH model using a dummy variable. This was introduced by (French et al., 1987) and showed that asymmetric adjustment was an important consideration with asset prices:

$$
\begin{aligned}
\mathrm{q}_{\mathrm{t}}= & \omega+\mathrm{P}\left(\mathrm{q}_{\mathrm{t}-1}-\omega\right)+\varnothing\left(\varepsilon_{\mathrm{t}-1}^{2}-\sigma_{\mathrm{t}-1}^{2}\right)+\theta_{1} \mathrm{z}_{1 \mathrm{t}} \\
\sigma_{\mathrm{t}}^{2}-\mathrm{q}_{\mathrm{t}-1}= & \alpha\left(\varepsilon_{\mathrm{t}-1}^{2}-\mathrm{q}_{\mathrm{t}-1}\right)+\gamma\left(\varepsilon_{\mathrm{t}-1}^{2}-\mathrm{q}_{\mathrm{t}-1}\right) \mathrm{d}_{\mathrm{t}-1} \\
& +\beta\left(\sigma_{\mathrm{t}-1}^{2}-\mathrm{q}_{\mathrm{t}-1}\right)+\theta_{2} \mathrm{z}_{2 \mathrm{t}}
\end{aligned}
$$

PGARCH: Power GARCH removes the restriction implicitly imposed by $\mathrm{ARCH} / \mathrm{GARCH}$, that is, the power transformation is achieved by taking squaring operations of the residual, it can possess richer volatility patterns such as asymmetry and leverage effects (Ding et al., 1993). Found that The PARCH model is applicable to these return indices and that the optimal power transformation is remarkably similar across countries:

$$
\sigma_{t}^{\rho}=\omega+\beta \sigma_{t-1}^{p}+\alpha\left(\left|\varepsilon_{t-1}\right|-\gamma \varepsilon_{t-1}\right)^{p}
$$

\section{MATERIALS AND METHODS}

Data: Trading in Tehran Stock Market (TSM) is based on orders sent by the brokers. Trading days in week are: Saturday, Sunday, Monday, Tuesday and Wednesday except national holidays. The data consist of 2375 daily observations of the closing value of the Tehran stock market from 3/30/1998 to 5/04/2007.

The return is calculated as:

$$
\mathrm{R}_{\mathrm{t}}=100 \log \left(\frac{\mathrm{p}_{\mathrm{t}}}{\mathrm{p}_{\mathrm{t}-1}}\right)
$$

where, $P_{t}$ is the value of index at time $t$. The residuals $\left(r_{t}\right)$ from the regression of $R_{t}$ on a constant and $R_{t-1}$, $\mathrm{R}_{\mathrm{t}-2} \ldots \mathrm{R}_{\mathrm{t}-12}$, are the unpredictable stock return data (The lag length in the mean equation is chosen by using Akaike's Information Criterion (AIC) and Final Prediction Error (FPE)). Table 2 shows summary statistics for $r_{t}$.

The unconditional mean of $r_{t}$ is zero by construction. The unconditional variance is 0.18 but visual inspections of the time series plot of the data Fig. 1 suggests that volatility of $r_{t}$ displays the

\begin{tabular}{|c|c|c|c|c|c|c|c|c|}
\hline$r_{t}$ & $\operatorname{var}\left(r_{t}\right)$ & Sk & $\mathrm{Ku}$ & B-J & $\mathrm{Q}(20)$ & $Q^{2}(20)$ & $R(5)$ & $\mathrm{A}(20)$ \\
\hline 0.00 & 0.18 & -0.57 & 48.04 & 111459.800 & 0.73 & 209.750 & 3.27 & 143.53 \\
\hline
\end{tabular}
clustering phenomenon associated with GARCH processes. Large shock (news) of either sign tends to be followed by large shocks and small shocks of either sign tend to follow small shocks.

There is significant evidence of ARCH in the data as shown by the test for 20th order ARCH and LjungBox Q statistic on the squared return data. There is, however, no evidence of serial correlation in the means,

Table 2: Summary statistics for $\mathrm{r}_{\mathrm{t}}$

Note: Marginal significance levels displayed as [.]; Sk and $\mathrm{Ku}$ are skewness and excess kurtosis; B-J is the Bera-Jarque test for normality distributed as $\chi^{2}(2)$; $\mathrm{Q}(20)$ and $\mathrm{Q}^{2}(20)$ are Ljung-Box for serial correlation in the returns and squared return data respectively, distributed as $\chi^{2}(20)$; $\mathrm{A}(20)$ is Engle and $\mathrm{Ng}$ (1993) test for seventh order ARCH, distributed as $\chi^{2}(20)$; R(5) is Ramsey's RESET test for non-linear dependence in the conditional mean of $r_{t}$ distributed as $\chi^{2}(4)$ 
Am. J. Applied Sci., 7 (1): 89-94, 2010

Table 3: Estimates of the volatility models

\begin{tabular}{|c|c|c|c|c|c|c|c|c|}
\hline & \multicolumn{4}{|c|}{ Normal (Gaussian) distribution } & \multicolumn{4}{|c|}{ Students't distribution } \\
\hline & TGARCH & EGARCH & Asym. CARCH & PGARCH & TGARCH & EGARCH & Asym. GARCH & PGARCH \\
\hline$\omega$ & $\begin{array}{c}0.002 \\
(1.706)\end{array}$ & $\begin{array}{c}-0.356 \\
(-4.687)\end{array}$ & $\begin{array}{c}0.962 \\
(0.108)\end{array}$ & $\begin{array}{c}0.007 \\
(1.802)\end{array}$ & $\begin{array}{c}0.002 \\
(3.191)\end{array}$ & $\begin{array}{c}-0.303 \\
(-7.959)\end{array}$ & $\begin{array}{c}1.853 \\
(206.000)\end{array}$ & $\begin{array}{c}0.007 \\
(2.174)\end{array}$ \\
\hline$\alpha$ & $\begin{array}{c}0.158 \\
(2.020)\end{array}$ & $\begin{array}{c}0.381 \\
(4.675)\end{array}$ & $\begin{array}{c}0.095 \\
(3.293)\end{array}$ & $\begin{array}{c}0.224 \\
(3.760)\end{array}$ & $\begin{array}{c}0.201 \\
(4.286)\end{array}$ & $\begin{array}{c}0.341 \\
(8.497)\end{array}$ & $\begin{array}{c}0.239 \\
(3.261)\end{array}$ & $\begin{array}{c}0.203 \\
(6.977)\end{array}$ \\
\hline$\beta$ & $\begin{array}{c}0.818 \\
(16.198)\end{array}$ & $\begin{array}{c}0.964 \\
(58.884)\end{array}$ & $\begin{array}{c}-0.881 \\
(-24.481)\end{array}$ & $\begin{array}{c}0.816 \\
(17.400)\end{array}$ & $\begin{array}{c}0.809 \\
(32.453)\end{array}$ & $\begin{array}{c}0.971 \\
(118.475)\end{array}$ & $\begin{array}{c}0.079 \\
(0.478)\end{array}$ & $\begin{array}{c}0.839 \\
(38.788)\end{array}$ \\
\hline$\gamma$ & $\begin{array}{c}0.090 \\
(1.38)\end{array}$ & $\begin{array}{c}-0.048 \\
(-1.001)\end{array}$ & $\begin{array}{c}-0.066 \\
(-1.749)\end{array}$ & $\begin{array}{c}0.111 \\
(0.819)\end{array}$ & $\begin{array}{c}0.043 \\
(0.735)\end{array}$ & $\begin{array}{c}-0.026 \\
(-0.985)\end{array}$ & $\begin{array}{c}-0.028 \\
(-0.326)\end{array}$ & $\begin{array}{c}0.067 \\
(0.798)\end{array}$ \\
\hline$\rho$ & - & - & $\begin{array}{c}0.997 \\
(37.944)\end{array}$ & $\begin{array}{c}1.237 \\
(3.275)\end{array}$ & - & - & $\begin{array}{c}0.999 \\
(207.856)\end{array}$ & $\begin{array}{c}1.055 \\
(4.590)\end{array}$ \\
\hline$\phi$ & - & - & $\begin{array}{c}0.198 \\
(3.748)\end{array}$ & - & - & - & $\begin{array}{c}0.149 \\
(5.392)\end{array}$ & - \\
\hline t-d.f & & & & 3.596 & $\begin{array}{c}3.647 \\
(9.389)\end{array}$ & $\begin{array}{c}3.917 \\
(9.740)\end{array}$ & (12.045) & $\begin{array}{c}3.611 \\
(9.641)\end{array}$ \\
\hline Log likelihood & -209.274 & -209.649 & -198.687 & -207.870 & -82.087 & -77.787 & -74.166 & -77.312 \\
\hline$Q(20)$ & 17.224 & 23.315 & 17.022 & 22.751 & 8.546 & 8.373 & 8.930 & 8.512 \\
\hline$p$-value & {$[0.638]$} & $(0.274)$ & $(0.652)$ & {$[0.301]$} & {$[0.988]$} & {$[0.989]$} & [0.984] & [0.988] \\
\hline Q2(20) & 7.913 & 6.695 & 10.038 & 8.376 & 6.988 & 6.277 & 4.666 & $\begin{array}{r}7.685 \\
50.0941\end{array}$ \\
\hline$p$-value & {$[0.990]$} & {$[0.998]$} & {$[0.967]$} & {$[0.989]$} & {$[0.997]$} & {$[0.998]$} & [0.999] & [0.994] \\
\hline $\mathrm{A}(20)$ & 8.148 & 6.819 & 10.478 & 8.624 & 7.189 & 6.303 & 4.766 & 7.714 \\
\hline p-value & {$[0990.000]$} & [0.997] & {$[0.956]$} & {$[0.987]$} & [0.996] & {$[0.998]$} & [0.999] & [0.994] \\
\hline Sk & 0.292 & 0.217 & 0.246 & 0.223 & 0.467 & 0.313 & 0.377 & 0.450 \\
\hline KU & 10.325 & 10.378 & 8.939 & 10.1202 & 12.777 & 13.404 & 12.526 & 14.045 \\
\hline $\begin{array}{l}\text { B-J } \\
\text { p-value }\end{array}$ & $\begin{array}{c}2965.520 \\
{[0.000]}\end{array}$ & $\begin{array}{r}3000.245 \\
{[0.000]}\end{array}$ & $\begin{array}{r}1950.088 \\
{[0.000]}\end{array}$ & $\begin{array}{r}2795.038 \\
{[0.000]}\end{array}$ & $\begin{array}{r}5297.239 \\
{[0.000]}\end{array}$ & $\begin{array}{c}5965.617 \\
{[0.000]}\end{array}$ & $\begin{array}{r}5014.723 \\
{[0.000]}\end{array}$ & $\begin{array}{c}6743.531 \\
{[0.000]}\end{array}$ \\
\hline
\end{tabular}

Notes: See notes to Table 2; z-statistics are displayed as (.)

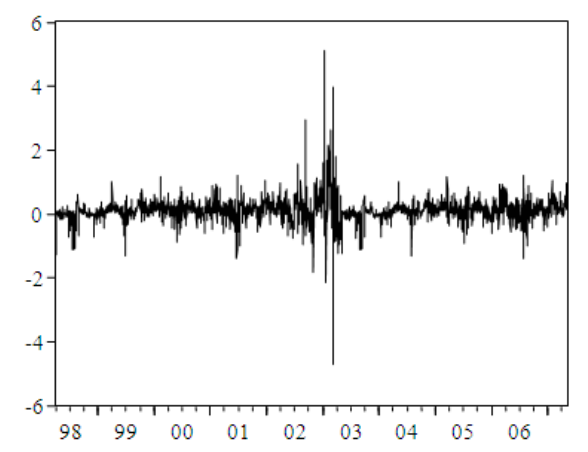

Fig. 1: Time series plot of $r_{t}$

as shown by Ljung-Box Q test statistic for the prefiltered return data. Furthermore, the null hypothesis of no higher order non-linear dependence in $r_{t}$, was satisfied at the 5\% level using Ramsey's (1969) RESET test. The unconditional density function for $r_{t}$ is skewed to left and leptokurtic when compared with the standard normal distribution as shown by the Bera-Jarq test for normality and Sk statistic for skewness.

\section{RESULTS AND DISCUSSION}

Estimation and results: To complete the basic $\mathrm{ARCH}$ specification, we require an assumption about the conditional distribution of the error term $\varepsilon$. There are three assumptions commonly employed when working with ARCH models: Normal (Gaussian) distribution, student's t-distribution and the Generalized Error Distribution (GED). Given a distributional assumption, $\mathrm{ARCH}$ models are estimated by the method of maximum likelihood.

The estimation and test results for the models defined in results are displayed in Table 3. The results suggest that the assumption of normally distributed standardized innovations, $z_{t}=\varepsilon_{t} / \sigma_{t}$, may be Tenuous.

The standardized residuals show evidence of excess kurtosis and the Bera-Jarque statistic strongly reject the hypothesis of normal distribution, so that we suspect that the residuals are not conditionally normally distributed. Therefore, to specify the form of the conditional distribution for errors, we also use student's $\mathrm{t}$ distribution to model the thick tail in residuals. Moreover, when we choose the conditional normal as the error distribution, Quasi-Maximum Likelihood (QML) covariance and standard errors is used (Bollerslev and Wooldridge, 1992)

The estimation and test results for all models suggest that the leverage effect term, $\gamma$ is not significant at 5\% level. Although, in Asym. CARCH model based on normal distribution for errors, the estimated coefficient on the asymmetry term is -0.066 with a $\mathrm{z}$ - 
Am. J. Applied Sci., 7 (1): 89-94, 2010

statistics of -1.749 recognized as significant at $10 \%$ level, but it has the wrong sign. It seems good news and bad news have the same effect on stock prices in TSM, a result that is in contrast to other studies for developed countries. Similar results were obtained using the generalized error distribution (For the GED, the loglikelihood contributions are of the form:

$$
\begin{aligned}
1_{t}= & -\frac{1}{2} \log \left[\frac{\Gamma(1 / r)^{3}}{\Gamma(3 / r)(r / 2)^{2}}\right]-\frac{1}{2} \log \sigma_{t}^{2} \\
& -\left[\frac{\Gamma(3 / r)\left(y_{t}-X_{t}^{\prime} \theta\right)^{2}}{\sigma_{t}^{2} \Gamma(1 / r)}\right]^{r / 2}
\end{aligned}
$$

where the tail parameter $r>0$. The GED is a normal distribution if $\mathrm{r}=2$. The tail parameter in different ARCH processes is estimated between1.05-1.07, implying that the distribution of the standardized errors is fat-tailed and departs significantly from normality). (not reported here). The results are not sensitive to the order of the asymmetric or threshold terms as well. So, the evidence is entirely conclusive. Moreover, none of "day-of-the week" effects are significant in mean or variance equation and the ARCH-M specification is not favorable to the presumption that the return contains a risk premium.

By the way, we see that the relatively small degrees of freedom parameter for the t-distribution suggests that the distribution of the standardized errors departs significantly from normality. ARCH processes with student's $t$ distribution for errors also outperform significantly the alternative ones according to the specification tests.

\section{CONCLUSSION}

This study applies several asymmetric volatility models as a metric for the specification of models of the conditional volatility of stock returns for the first time in Tehran stock market. The estimated models containing TGARCH, EGARCH, asymmetric GARCH and PGARCH with different assumptions on error distributions suggest no strong and significant asymmetric effect. This conclusion is contrary to the existing evidence of significant leverage effect in the bulk of literature. There are some reasons for this finding:

- In Iran with Islamic laws, debt contracts are illegal or at least not enforced. So Iranian firms do not have financial leverage. As a result, we would expect to find smaller leverage effects in volatility in Iran than in the western countries. In deed the institutional differences with western financial markets manifest themselves in different return characteristics

- Stock prices in the TSM by regulation and intervention cannot exceed from some range. The strong serial correlation in returns necessitating long lags in mean equations are possibly due to such regulations

- The history of TSM is very short compared to other stock markets and the information flow in this market is very slow. The estimated coefficients on the expected risk (as a measure of the risk-return tradeoff) and dummy variable for Saturday which is meant to capture weekend non-trading are not significant.

\section{REFRENCES}

Black, F., 1976. Studies of stock price volatility changes. Proceeding of the Meetings of the Business and Economic Statistics Section, (MBESS' 76), American Statistical Association, USA., pp: 177-181.

Bollerslev, T. and J. Wooldridge, 1992. Quasimaximum likelihood estimation and inference in dynamic models with time-varying covariances. Econ. Rev., 11: 143-172. DOI: 10.1080/07474939208800229

Bollerslev, T., 1986. Generalized autoregressive conditional heteroskedasticity. J. Econ., 31: 307-327. DOI: 10.1016/0304-4076(86)90063-1

Bollerslev, T., R.F. Engle and D.B. Nelson, 1994. Chapter 49 arch models. Handbook Econ., 4: 2959-3038. DOI: $10.1016 / \mathrm{S} 1573-$ 4412(05)80018-2

Bollerslev, T., R.Y. Chou and K.F. Kroner, 1992. ARCH modeling in finance. J. Econ., 52: 5-59. DOI: 10.1016/0304-4076(92)90064-X

Campbell, J.Y. and L. Hentschel, 1992. No news is good news: An asymmetric model of changing volatility in stock returns. J. Finance. Econ., 31: 281-318. http://www.nber.org/papers/w3742.pdf

Christle, A.A., 1982. The stochastic behavior of common stock variances-value, leverage and interest rate effects. J. Fin. Econ., 10: 407-432. DOI: 10.1016/0304-405X (82)90018-6

Cox, J.C. and S.A. Ross, 1976. The valuation of options for alternative stochastic processes. J. Fin. Econ., 3: 145-166. DOI: 10.1016/0304-405X (76)90023-4 
Dickey, D.A. and W.A. Fuller, 1979. Distribution of estimators for autoregressive time series with a unit root. J. Am. Stat. Assoc., 74: 427-431. DOI: $10.2307 / 2286348$

Ding, Z., C.W.J. Granger and R.F. Engle, 1993. A long memory property of stock market returns and a new model. J. Empirical Finance, 1: 83-106. DOI: 10.1016/0927-5398(93)90006-D

Ding, Z., C.W.J. Granger, 1996. Modeling volatility persistence of speculative returns: A new approach. J. Econ., 73: 185-215. DOI: 10.1016/03044076(95)01737-2

Engle, R.F. and V.K. Ng, 1993. Measuring and testing the impact of news on volatility. J. Finance, 48: 1749-1778. http://www.jstor.org/pss/2329066

French, K.R., G.W. Schwert and R. Stambaugh, 1987. Expected stock returns and volatility. J. Finance Econ., 19: 3-29. DOI: 10.1016/0304405X(87)90026-2

Friedmann, R. and W.G. Sanddorf-Köhle, 2002. Volatility clustering and nontrading days in Chinese stock markets. J. Econ. Bus., 54: 193-217. DOI: 10.1016/S0148-6195(01)00062-5

Glosten, L.R., R. Jagannathan and D.E. Runkle, 1993. On the relation between the expected value and the volatility of the nominal excess returns on stocks. J. Finance, 48: 1779-1801. http://www.jstor.org/pss/2329067

Harvey, C.R. and A. Siddique, 1999. Autoregressive conditional skewness. J. Finance Quant. Anal., 34: 465-487. DOI: $10.2307 / 2676230$
Henry, O., 1998. Modeling the asymmetry of stock market volatility. Applied Fin. Eco., 8: 145-153. DOI: $10.1080 / 096031098333122$

Kwiatkowski, D., P.C.B. Phillips, P. Schmidt and Y. Shin, 1992. Testing the null hypothesis of stationary against the alternative of a unit root: How sure are we that economic time series have a unit root. J. Econ., 54: 159-178. DOI: 10.1016/0304-4076(92)90104-Y

Nelson, D.B., 1991. Conditional heteroskedasticity in asset returns: A new approach. Econometrica, 59: 347-370. http://www.jstor.org/pss/2938260

Pagan, A.R. and G.W. Schwert, 1990. Alternative models for conditional stock volatility. J. Econ., 45: 267-290. Doi: 10.1016/0304-4076(90)90101-X

Panagiotidis, T., 2002. Testing the assumption of linearity. Econ. Bull., 3: 1-9. http://www.jstor.org/pss/2938260

Pindyck, R.S., 1984. Risk, inflation and the stock market. Am. Econ. Rev., 74: 335-351. http://www.jstor.org/pss/1804011

Schwert, G.W., 1989. Why does stock market volatility change over time. J. Finance, 44: 1115-1153. http://www.jstor.org/pss/2328636

$\mathrm{Wu}$, G., 2002. The determinants of asymmetric volatility. Rev. Finance Stud., 14: 837-859. http://EconPapers.repec.org/RePEc:oup:rfinst:v:14: y:2001:i:3:p:837-59 